\title{
Second line (disease modifying) treatment in rheumatoid arthritis: which drug for which patient?
}

\author{
H A Capell, D R Porter, R Madhok, J A Hunter
}

\begin{abstract}
Objectives-The objectives were to assess (a) the comparative merits of commonly used disease modifying drugs in the treatment of rheumatoid arthritis (RA) and (b) the influence of age, gender, and disease duration on the outcome of treatment.

Methods-Collected analysis (metaanalysis) was performed on results obtained during the first year of treatment in 1140 patients with RA treated with gold, penicillamine, sulphasalazine, or auranofin from a single centre.

Results-Gold, penicillamine, and sulphasalazine performed similarly, with about $60 \%$ of patients continuing to receive each of these drugs for at least one year. Neither gender nor age had an influence on the response to treatment, but patients with a longer disease duration showed a greater tendency to stop treatment. The median percentage improvement was $33 \%$ in visual analogue pain score and $50 \%$ in erythrocyte sedimentation rate.

Conclusions-Routine use of these drugs should at least equal these results. Any new drug should either be substantially less toxic or at least as efficacious.
\end{abstract}

(Ann Rheum Dis 1993; 52: 423-428)

Second line (disease modifying) antirheumatic drugs are widely used in the management of active rheumatoid arthritis (RA) and information about the relative efficacy and toxicity of available drugs is needed. Such information would be valuable to rheumatologists, general practitioners, and patients. Previous comparative studies of disease modifying drugs have been criticised because of inadequate numbers resulting in insufficient power to avoid a type II error. This has led to the use of meta-analyses. ${ }^{1}$ Problems which arise with such meta-analyses include variations in enrolment criteria, in parameters used to make decisions about the continuation of treatment and in possible ethnic differences in responses to treatment. For this reason a collected analysis of prospective studies from a single centre may provide greater numbers than are available from comparative studies and at the same time more comprehensive and uniform data than is achieved by meta-analysis.
Previous studies from a single centre have shown high drop out rates from these treatments in the first year, ${ }^{23}$ a finding of considerable concern to rheumatologists. If these drugs are to 'modify' RA, long term treatment is necessary, and the initial treatment period is associated with the highest drop out rates. It therefore seemed important to analyse results from a different single centre.

In addition, concern is often expressed about the influence of age, disease duration, gender, and initial disease activity on the likelihood of continuing to receive treatment with disease modifying drugs and on the response to such treatment. ${ }^{45} \mathrm{~A}$ large cohort of patients allows analysis of demographic variables which might assist in predicting the usefulness of treatment in different patient groups.

This collected analysis thus aims to compare clinical and laboratory response to intramuscular gold, penicillamine, sulphasalazine, and auranofin and to assess the effect of age, disease duration, gender, and initial erythrocyte sedimentation rate (ESR) on the response to treatment. This paper concentrates on the first year of treatment-the time when most problems arise with such treatments and during which long term treatment is compromised if high drop out rates occur. The long term use of disease modifying drugs is required to maximise their protective effects on joints and to minimise disability related to joint damage.

\section{Patients and methods}

A collected analysis of all 1140 patients entered into prospective, randomised studies of 'established' drugs between 1981 and 1991 at the Centre for Rheumatic Diseases, Royal Infirmary and at Gartnavel General Hospital, Glasgow has been performed. The indication for disease modifying drugs was active synovitis in patients with RA inadequately controlled by symptom relieving non-steroidal antiinflammatory drugs (NSAIDs) alone. All studies were prospective and randomised. Systemic corticosteroids were not used although intra-articular steroid injections were allowed (a maximum of three injections in any six month period). Most patients (1020) were assessed by a single nurse metrologist. One hundred and twenty were seen by two other nurse metrologists in the same unit. Clinical measurements included pain score, duration 
of morning stiffness, and Ritchie articular index. Laboratory parameters analysed were haemoglobin, ESR, platelet count, and, in studies conducted since $1984, \mathrm{C}$ reactive protein.

Five hundred patients received intramuscular gold: 30 from a study of gold $v$ sulphasalazine $v$ placebo, ${ }^{6} 30$ from gold $v$ auranofin $v$ placebo, ${ }^{7}$ and 440 from gold plus hydroxychloroquine or placebo. ${ }^{8}$

Three hundred and fifty two patients received sulphasalazine: 30 from a study of intramuscular gold $v$ sulphasalazine or placebo, ${ }^{6} 60$ from a dose ranging study, ${ }^{9} 60$ from an acetylator status study, ${ }^{10} 102$ from a comparison with penicillamine, ${ }^{11}$ and 100 from a comparison with auranofin. ${ }^{12}$

One hundred and fifty eight patients received penicillamine: 60 from a dose ranging study ${ }^{13}$ and 98 from the above study comparing sulphasalazine with penicillamine. ${ }^{11}$

One hundred and thirty patients received auranofin: 30 from the study noted above ${ }^{7}$ and 100 from a study comparing auranofin with sulphasalazine. ${ }^{12}$

There were three chronological cohorts of sulphasalazine with approximately equal numbers. One hundred and fifty patients were studied between 1981 and $1984,{ }^{6910} 152$ between 1985 and $1987,{ }^{11}$ and 100 between 1988 and $1990,{ }^{12}$ allowing the assessment of possible changes over this period. Such changes have been noted by others with gold treatment. ${ }^{14}$

Intramuscular gold was given first as a $10 \mathrm{mg}$ test dose, then $50 \mathrm{mg}$ weekly until a response was obtained, when the frequency of injections was decreased. Maintenance injections were in most instances given once every four weeks. The dose of penicillamine was started at $125 \mathrm{mg}$ daily and increased by $125 \mathrm{mg}$ each month until a response was seen, side effects supervened, or the maximum dose of $1000 \mathrm{mg} /$ day was reached. Enteric coated sulphasalazine was started at $0.5 \mathrm{~g}$ daily with weekly increments of $0.5 \mathrm{~g}$ until the target dose of $40 \mathrm{mg} / \mathrm{kg}$ in divided doses was reached or side effects necessitated dose adjustment (an exception to this was in the dose ranging study). In the absence of a response the dose was increased to a maximum of $4 \mathrm{~g}$ after six months. Auranofin was started at $3 \mathrm{mg}$ twice a day and increased to a maximum of $3 \mathrm{mg}$ three times a day if the response was insufficient between three and six months. General patient care and specific monitoring for toxicity was shared with the general practitioner unless the general practitioner or the patient did not agree to this arrangement. Patients were seen at least once every three or four months at a specialist rheumatology clinic.
A proportion of the patients treated with gold were treated with a combination of either hydroxychloroquine or placebo between six and 12 months. This did not alter the outcome $^{8}$ and the patients have therefore been included in this collected analysis.

\section{ANALYSIS OF DATA}

Drop outs

The number of patients continuing treatment were compared using lifetable analysis: both between individual drugs and for the three chronologically distinct cohorts of patients treated with sulphasalazine as outlined earlier. Patients treated with placebo in various studies from the unit were used for comparison. ${ }^{15} 16$

\section{Efficacy}

Within group changes of clinical and laboratory parameters of inflammation were analysed using the Wilcoxon matched pairs signed rank test between 0-3, 0-6, and 0-12 months.

\section{Relative efficacy}

Between group analysis at zero, three, six, and 12 months was performed using the Kruskal Wallis test. In addition to calculating medians and ranges for all parameters the means and confidence intervals for gold and sulphasalazine were also calculated.

\section{Demographic features}

Logistic regression was used to assess the relative effects of age, disease duration, gender, and initial ESR on the likelihood of stil receiving treatment at one year. For this purpose the gold, penicillamine, and sulphasalazine groups were combined to give a potential study group of 1010 patients. The following subgroups were analysed: (a) ageless than $45,45-60$, and $>60$ years; $(b)$ disease duration-less than three, 4-10, and $>10$ years; (c) men $v$ women; $(d)$ initial ESR $<30$ or $>30 \mathrm{~mm} / \mathrm{h}$.

Each parameter was assessed at the outset and the change between $0-3,0-6$, and $0-12$ months in relation to age, disease duration, and gender was determined.

\section{Results}

There was no significant difference between the four treatment groups in demographic variables at the outset, with similar ages, disease durations, and sex ratios (table 1). Overall, $291(26 \%)$ of the patients took part in more than one study.

Table 1 Demographic features in patients beginning treatment with disease modifying drugs for rheumatoid arthritis in Glasgow 1981-91

\begin{tabular}{lcccc}
\hline & $\begin{array}{c}\text { Intramuscular gold } \\
(n=500)\end{array}$ & $\begin{array}{c}\text { Sulphasalazine } \\
(n=352)\end{array}$ & $\begin{array}{c}\text { Penicillamine } \\
(n=158)\end{array}$ & $\begin{array}{c}\text { Auranofin } \\
(n=130)\end{array}$ \\
\hline Median (range) age (years) & $57(19-86)$ & $57(20-79)$ & $57(18-81)$ & $55(20-82)$ \\
Median (range) disease duration (years) & $6(0-66)$ & $8(1-57)$ & $\begin{array}{c}7(0-31) \\
9(0-42)\end{array}$ & $108(83)$ \\
No (\%) women & $385(77)$ & $275(78)$ & $122(77)$ & 1080 \\
\hline
\end{tabular}




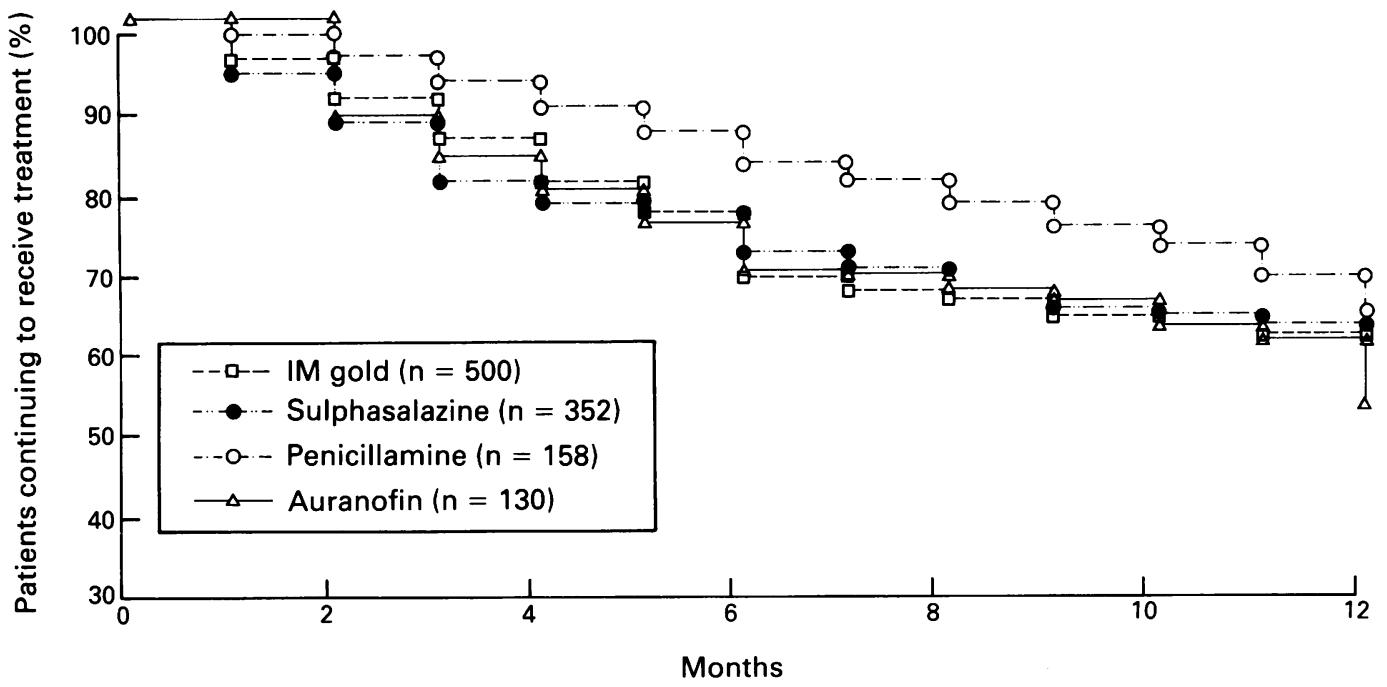

Figure 1 Lifetable analysis during first year of treatment. IM gold=intramuscular gold.

DROP OUTS

The proportion of patients continuing treatment over the first year are shown in the lifetable analysis curves (fig 1). At six months $68 \%$ of patients were still receiving intramuscular gold, $82 \%$ penicillamine, $71 \%$ sulphasalazine, and $69 \%$ auranofin. This contrasts with the patients treated with placebo where only $46 \%$ were still receiving treatment at six months. ${ }^{16}$ By 12 months $59 \%$ were still receiving intramuscular gold, $64 \%$ penicillamine, $61 \%$ sulphasalazine, and $52 \%$ auranofin. Only the auranofin group differed significantly from the other three drug treatment groups.

Table 2 gives a summary of the reasons for discontinuation of treatment in the first 12 months. Fewer patients discontinued intramuscular gold because of a lack or loss of effect than auranofin $\left(\chi^{2} 15.5 ; p<0.0001\right)$. Table 3 gives the results from sequential sulphasalazine studies; no differences were observed over the period.

EFFICACY

Table 4 gives the clinical and laboratory parameters for the four drug groups ( $\mathrm{C}$ reactive

Table 2 Reasons for discontinuation of treatment: 0-12 months

\begin{tabular}{lllll}
\hline \multicolumn{5}{l}{ No (\%) discontinuing treatment } \\
\cline { 2 - 5 } & $\begin{array}{l}\text { Intramuscular gold } \\
(n=500)\end{array}$ & $\begin{array}{l}\text { Sulphasalazine } \\
(n=352)\end{array}$ & $\begin{array}{l}\text { Penicillamine } \\
(n=158)\end{array}$ & $\begin{array}{l}\text { Auranofin } \\
(n=130)\end{array}$ \\
\hline Adverse events & $150(30)$ & $92(26)$ & $38(24)$ & $40(31)$ \\
Lack/loss of effect & $10(2)$ & $28(8)$ & $13(8)$ & $14(11)$ \\
Other & $40(8)$ & $18(5)$ & $6(4)$ & $8(6)$ \\
Total & $200(40)$ & $137(39)$ & $57(36)$ & $62(48)$ \\
\hline
\end{tabular}

^Includes intercurrent illness, death from unrelated causes, lack of compliance, or moved away.

Table 3 Reasons for discontinuation of treatment: sulphasalazine sequential studies 1981-90

\begin{tabular}{llccc}
\hline \multicolumn{5}{l}{$N o(\%)$ discontinuing treatment } \\
\cline { 2 - 5 } & $1981-3$ & $1984-6$ & $1987-90$ & Total \\
\hline Adverse events & $40(27)$ & $25(25)$ & $28(28)$ & $93(26)$ \\
Lack/loss effect & $13(9)$ & $8(8)$ & $7(7)$ & $28(8)$ \\
Other & $9(5)$ & $5(5)$ & $2(2)$ & $16(5)$ \\
Total & $62(41)$ & $38(37)$ & $37(37)$ & $137(39)$ \\
\hline
\end{tabular}

protein was not available for all patients). All parameters showed a significant improvement at six months and one year (Wilcoxon $\mathrm{p}<0 \cdot 0001)$. There was no significant difference between the groups for any variable or in the degree of change in any variable for the patients who continued treatment, though it should be noted that more patients had stopped taking auranofin because of a lack of effect. Table 5 gives the median percentage improvement in haemoglobin, platelets, ESR, $\mathrm{C}$ reactive protein, and visual analogue pain score $(0-3,0-6$, and 0-12 months).

Comparison of changes in ESR in the four treatment groups and previous collected analysis of 142 patients treated with placebo, ${ }^{16}$ is shown in fig 2 , with a striking difference between the patients treated with placebo and the active treatments.

\section{DEMOGRAPHIC ANALYSIS}

As intramuscular gold, penicillamine, and sulphasalazine groups behaved in a remarkably similar way these were combined for the demographic analysis (table 6). Although there was a trend for the older patients to be less likely to continue treatment, this did not reach significance. There was also a trend for patients with longer disease duration to be more likely to discontinue treatment and this reached significance at $p<0 \cdot 05$. Male and female patients were remarkably similar in their likelihood of continuing treatment when other variables were taken into account. In contrast, those subjects with a higher initial ESR were more likely to continue treatment.

The influence of age, disease duration, and gender on initial clinical and laboratory variables and the change over three, six, and 12 months was analysed. Details are available but are not shown here.

\section{Age}

Older patients were more likely to have longer disease duration, as expected. They also had significantly lower haemoglobin and higher ESR levels but the change in haemoglobin and 
Table 4 Clinical features at zero, six, and 12 months (median values)

\begin{tabular}{|c|c|c|c|c|c|c|c|c|c|c|c|c|}
\hline & \multicolumn{3}{|c|}{$\begin{array}{l}\text { Intramuscular gold } \\
(n=500)\end{array}$} & \multicolumn{3}{|c|}{$\begin{array}{l}\text { Sulphasalazine } \\
(n=352)\end{array}$} & \multicolumn{3}{|c|}{$\begin{array}{l}\text { Penicillamine } \\
(n=158)\end{array}$} & \multicolumn{3}{|c|}{$\begin{array}{l}\text { Auranofin } \\
(n=130)\end{array}$} \\
\hline & $\overline{0}$ & 6 & 12 & $\overline{0}$ & 6 & 12 & $\overline{0}$ & 6 & 12 & $\overline{0}$ & 6 & 12 \\
\hline Haemoglobin $(\mathrm{g} / \mathrm{l})$ & 118 & 123 & 126 & 114 & 120 & 119 & 116 & 123 & 123 & 117 & 119 & 120 \\
\hline Platelet count $\left(\times 10^{9} / 1\right)$ & 407 & 338 & 324 & 419 & 333 & 332 & 406 & 321 & 321 & 416 & 349 & 330 \\
\hline Erythrocyte sedimentation rate $(\mathrm{mm} / \mathrm{h})$ & 56 & 30 & 25 & 61 & 30 & 30 & 62 & 33 & 33 & 51 & 31 & 30 \\
\hline $\mathrm{C}$ Reactive protein $(\mathrm{mg} / \mathrm{l})$ & 39 & 16 & 13 & 40 & 11 & 16 & - & - & - & 33 & 16 & 15 \\
\hline Ritchie articular index & 14 & 6 & 5 & 16 & 6 & 6 & 21 & 9 & 6 & 14 & 9 & 4 \\
\hline Visual analogue pain score & 180 & 135 & 117 & 180 & 135 & 137 & 204 & 144 & 144 & 195 & 142 & 105 \\
\hline Duration of morning stiffness ( $\mathrm{min}$ ) & 120 & 30 & 30 & 90 & 30 & 30 & 120 & 60 & 30 & 120 & 30 & 20 \\
\hline
\end{tabular}

Within group analysis: improvement in all groups, for all variables $0-6$ and 0-12 months. Wilcoxon $<0.0001$ throughout. Between groups analysis: no significant differences between groups for any variable, except higher articular index in penicillamine group at month 0 (Kruskal Wallis $\mathrm{p}<0 \cdot 05$ ).

Table 5 Median (percentage) improvement in laboratory and clinical features at 0-3, 0-6 and 0-12 months

\begin{tabular}{|c|c|c|c|c|c|c|c|c|c|c|c|c|}
\hline & \multicolumn{3}{|c|}{$\begin{array}{l}\text { Intramuscular gold } \\
(n=500)\end{array}$} & \multicolumn{3}{|c|}{$\begin{array}{l}\text { Sulphasalazine } \\
(n=352)\end{array}$} & \multicolumn{3}{|c|}{$\begin{array}{l}\text { Penicillamine } \\
(n=158)\end{array}$} & \multicolumn{3}{|c|}{$\begin{array}{l}\text { Auranofin } \\
(n=130)\end{array}$} \\
\hline & $0-3$ & $0-6$ & $0-12$ & $0-3$ & $0-6$ & $0-12$ & $0-3$ & $0-6$ & $0-12$ & $0-3$ & $0-6$ & $0-12$ \\
\hline Haemoglobin $(\mathrm{g} / \mathrm{l})$ & 20 & 40 & 50 & 0 & 20 & 30 & 10 & 60 & 60 & 30 & 10 & 20 \\
\hline Platelet count $\left(\times 10^{9} / 1\right)$ & 8 & 18 & 21 & 12 & 20 & 21 & 12 & 21 & 25 & 5 & 14 & 18 \\
\hline Erythrocyte sedimentation rate $(\mathrm{mm} / \mathrm{h})$ & 34 & 47 & 57 & 35 & 49 & 43 & 28 & 40 & 46 & 13 & 31 & 37 \\
\hline C Reactive protein $(\mathrm{mg} / \mathrm{l})$ & 31 & 48 & 50 & 50 & 53 & 38 & $\mathrm{NA}^{\star}$ & $\mathrm{NA}^{\star}$ & $\mathrm{NA}^{\star}$ & 11 & 33 & 38 \\
\hline Visual analogue pain score & 23 & 32 & 33 & 16 & 31 & 31 & 22 & 30 & 31 & 11 & 28 & 35 \\
\hline
\end{tabular}

$\star \mathrm{NA}=$ Not available.

in ESR in the three age groups was remarkably similar.

The most striking difference with age was in $C$ reactive protein, which was higher in older patients at the outset of treatment and at six and 12 months.

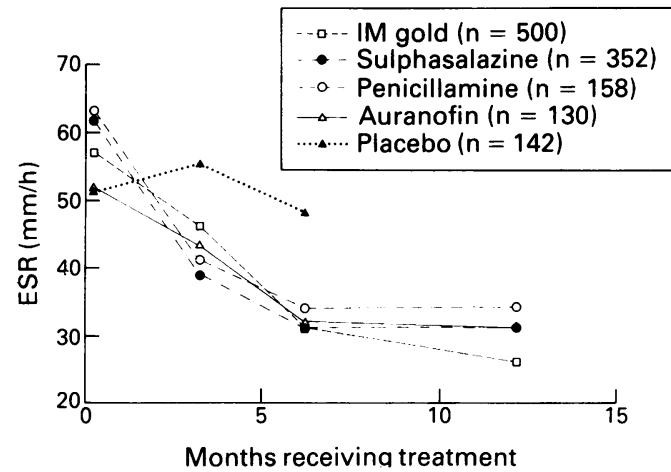

Figure 2 Collected analysis of treatment of patients with rheumatoid arthritis with disease modifying drugs. Changes in median erythrocyte sedimentation rate over the first year of treatment. IM gold=intramuscular gold.

\section{Disease duration}

As expected, there was an excess of older patients in those with longer disease duration. In addition, the group with longer disease duration had a higher articular index at the outset. In contrast, those with early disease had a higher platelet count and ESR. Nevertheless, the changes in articular index, platelets, and ESR for the groups of patients with disease less than three, 4-10, and $>10$ years was not significantly different except for the change in ESR and platelets at $0-3$ months, which was slightly greater in the group with early disease.

\section{Gender}

The ESR was higher in women and the haemoglobin higher in men, but the changes in ESR and haemoglobin were equivalent for male and female patient groups.

\section{Discussion}

Previous lifetable analyses with smaller groups of patients from a single centre have suggested

Table 6 Influence of age, disease duration, sex ratio, and initial erythrocyte sedimentation rate (ESR) on relative probability of continuing treatment in first year. Combining intramuscular gold, penicillamine, and sulphasalazine $(n=1010)$ (logistic regression)

\begin{tabular}{|c|c|c|c|}
\hline & $\begin{array}{l}\text { Percentage of } \\
\text { treatment group }\end{array}$ & $\begin{array}{l}\text { Relative probability } \\
\text { of continuing treatment }\end{array}$ & Logistic regression \\
\hline $\begin{array}{c}\text { Age (years) } \\
<45 \\
45-59 \\
>60\end{array}$ & $\begin{array}{l}20 \\
45 \\
35\end{array}$ & $\begin{array}{l}1 \cdot 0 \\
0.9 \\
0 \cdot 81\end{array}$ & NS \\
\hline $\begin{array}{c}\text { Disease du } \\
0-3 \\
4-10 \\
>10\end{array}$ & $\begin{array}{l}30 \\
36 \\
34\end{array}$ & $\begin{array}{l}1 \cdot 0 \\
0 \cdot 77 \\
0 \cdot 71\end{array}$ & $\begin{array}{l}\mathrm{p}<0.05 \\
\text { Those with longer disease duration more likely } \\
\text { to discontinue treatment }\end{array}$ \\
\hline $\begin{array}{l}\text { Sex ratio } \\
\quad \mathbf{M} \\
\mathbf{F}\end{array}$ & $\begin{array}{l}22 \\
78\end{array}$ & $\begin{array}{l}1.0 \\
1.0\end{array}$ & NS \\
\hline $\begin{array}{l}\text { ESR } \\
\quad<30 \\
30-60 \\
>60\end{array}$ & $\begin{array}{l}18 \\
34 \\
48\end{array}$ & $\begin{array}{l}1 \cdot 0 \\
1 \cdot 38 \\
1 \cdot 45\end{array}$ & $\begin{array}{l}\mathrm{p}<0.05 \\
\text { Those with higher ESR more likely to continue } \\
\text { treatment }\end{array}$ \\
\hline
\end{tabular}


that the outlook in terms of the likelihood of continuing treatment with standard disease modifying drugs is poor. The results in this collected analysis are different from those reported by Grindulis and McConkey ${ }^{2}$ and Situnayake $e t a l^{3}$ and the reasons for this are not clear. Sambrook et $a l^{17}$ and Thompson et $a l^{18}$ have also reported an approximately $50 \%$ drop out in the first year in patients receiving gold and penicillamine in a single centre. The relevance of concurrent corticosteroid treatment is difficult to assess. No patient in the Glasgow studies was receiving systemic corticosteroids, whereas 35 of 251 $(14 \%)$ patients in London ${ }^{18}$ received steroids. Sambrook et $a l^{17}$ analysed withdrawals with respect to steroid treatment and concluded that there was no significant difference compared with the non-steroid treatment group.

The influence of a nurse metrologist is likely to have a positive effect on compliance, though this is difficult to evaluate. She is a 'constant' figure in the studies, even though the medical care was supervised by a number of hospital doctors and many hundreds of general practitioners.

As the sequence of studies using sulphasalazine shows, however, the results reported here are entirely reproducible and should be achieved in a routine setting with general practitioner 'shared care'. It would, of course, be desirable to improve these results and in the future this might be possible. ${ }^{2}$

The comparative analysis has shown that the likelihood of continuing treatment for one year is remarkably similar with intramuscular gold, penicillamine, or sulphasalazine when these drugs are used in the treatment of RA. The degree of response to treatment is similar for all three drugs. Although haemoglobin changes very little, an approximately $50 \%$ improvement in the ESR and $\mathrm{C}$ reactive protein can be expected and a $30 \%$ improvement in the visual analogue pain score. Auranofin performs slightly less well with a slower response and more patients stopping treatment because of inefficacy; the subgroup who continue treatment have an effect equivalent to the other drugs at one year. In addition, in one of the auranofin studies, 26 patients had previously received intramuscular gold and this might have been a confounding factor. Thus other considerations such as the rapidity of onset of benefit (probably more rapid with sulphasalazine than intramuscular gold, penicillamine, or auranofin) $)^{12}$ or the ability to ensure compliance with intramuscular gold should dictate the choice of drug. In addition, the incidence of severe or life threatening side effects will be important in the choice of a particular drug and this has not been addressed in this study. No cumulative side effect has been reported with gold, penicillamine, or sulphasalazine and this too would influence the way these drugs are used relative to cytotoxic drugs or systemic corticosteroids.

Although patients with a longer disease duration or lower ESR were less likely to continue treatment, age and gender had little effect on drug tolerability and older patients should be offered disease modifying treatment providing there are no contraindications. The results with respect to gender are contrary to those of Wolfe and Hawley ${ }^{19}$ who concluded from a smaller cohort that women do less well with disease modifying drugs.

Despite intensive research it is unlikely that targeted treatment will be available in the immediate future. ${ }^{20}$ Nevertheless, several new drugs are currently being studied for disease modifying effects. Such drugs should at least equal the number of patients continuing treatment with existing disease modifying drugs in the crucial early stages, or should offer significantly lower toxicity. For the optimum use of currently available disease modifying drugs an analogy with treatment for hypertension can be drawn, where the goals are directed at optimum blood pressure control to reduce long term morbidity. Currently available drugs, with the exception of hydroxychloroquine, have been shown to retard radiological progression, ${ }^{21-23}$ and a long term follow up study from our centre has shown that it is possible to maintain patients on disease modifying drugs over 10 years. ${ }^{24}$ Improvement with this group of drugs is undoubtedly greater than with placebo. ${ }^{15} 25$ This analysis has shown that intramuscular gold, penicillamine, and sulphasalazine perform similarly over a period of one year and that men and women of any age, and even those with long disease duration, may benefit from a disease modifying drug.

We thank Mrs D McKnight for the computing, Dr David Hole for his help with statistical analysis, Sister A Thomson and Sister M Morrison who assisted in the metrology, Professor $R$ Sturrock for allowing the study of patients in his care, all the medical staff who have assisted in caring for the patients, and Miss A Tierney for typing the manuscript.

1 Felson D T, Anderson J J, Meenan R F. The comparative efficacy and toxicity of second-line drugs in rheumatoid arthritis. Arthritis Rheum 1990; 33: 1449-61.

2 Grindulis K A, McConkey B. Outcome of attempts to treat rheumatoid arthritis with gold, penicillamine, sulphasalazine or dapsone. Ann Rheum Dis 1984; 43: 398-401.

3 Situnayake R D, Grindulis K A, McConkey B. Long term treatment of rheumatoid arthritis with sulphasalazine, gold, or penicillamine: a comparison using life-table methods. Ann Rheum Dis 1987; 46: 177-83.

4 van der Heijde D M F M, van Riel P L C M, van Rijswijk $M \mathrm{H}$, van de Putte L B A. Influence of prognostic features on the final outcome in rheumatoid arthritis: a review of on the final outcome in rheumatoid arthritis: a review

5 Wolfe F, Hawley D J, Cathey M A. Termination of slow acting antirheumatic therapy in rheumatoid arthritis: a 14 year prospective evaluation of 1017 consecutive starts. f Rheumatol 1990; 17: 994-1002.

6 Pullar T, Hunter J A, Capell H A. Sulphasalazine in rheumatoid arthritis: a double blind comparison of sulphasalazine with placebo and sodium aurothiomalate. $B M F$ 1983; 287: 1102-4.

7 Capell H A, Lewis D, Carey J. A three year follow up of patients allocated to placebo, or oral or injectable gold therapy for rheumatoid arthritis. Ann Rheum Dis 1986; 45: 705-11.

8 Porter D R, Hunter J A, Capell H A A double blind controlled trial of adding hydroxychloroquine or placebo to patients with a suboptimal response after 6 months of to patients with a suboptimal response after 6 months of

9 Pullar T, Hunter J A, Capell H A. Sulphasalazine in the treatment of rheumatoid arthritis: relationship of dose and serum levels to efficacy. $\mathrm{Br} \mathcal{F}$ Rheumatol 1985; 24: 269-76.

10 Pullar T, Hunter J A, Capell H A. Effect of acetylator phenotype on efficacy and toxicity of sulphasalazine in rheumatoid arthritis. Ann Rheum Dis 1985; 44: 831-7.

11 Capell H A, Marabani M, Madhok R, Torley H, Hunter J A. Degree and extent of response to sulphasalazine or penicillamine therapy for rheumatoid arthritis: results from a routine clinical environment over a two year period. $Q \mathcal{F}$ Med 1990; 75: 335-44

12 Porter D, Madhok R, Hunter J A, Capell H A. Prospective trial comparing the use of sulphasalazine and auranofin as second line drugs in patients with rheumatoid arthritis. Ann Rheum Dis 1992; 51: 461-4. 
13 Madhok R, Zoma A, Torley H I, Capell H A, Waring R, Hunter J A. The relationship of sulfoxidation status to efficacy and toxicity of penicillamine in the treatment of rheumatoid arthritis. Arthritis Rheum 1990; 30: 574-7.

14 Bendix G, Bjelle A. Outcome of parenteral gold therapy in RA patients: a comparison between two periods using lifeRA patients: a comparison between two periods

15 Pullar T, Capell H A. A rheumatological dilemma: is it possible to modify the course of rheumatoid arthritis? Can we answer the question? Ann Rheum Dis 1985; 44: 134-40.

16 Porter D R, Capell $\mathrm{H} \mathrm{A}$. The magnitude of the placebo effect in trials of disease modifying drugs (DMARDs) in rheumatoid arthritis (RA): results from a single uni [abstract]. Arthritis Rheum 1991; 34 (suppl): 5127.

17 Sambrook P N, Browne C D, Champion G D, Day R O, Vallance J B, Warwick $N$. Terminations of treatment with gold sodium thiomalate

18 Thompson P W, Kirwan J R, Barnes C G. Practical results of treatment with disease-modifying antirheumatoid of treatment with disease-modifying

19 Wolfe F, Hawley D J. Remission in rheumatoid arthritis. f Rheumatol 1985; 12: 245-52.
20 Capell H A, Brzeski M. Slow drugs: slow progress? Use of slow acting antirheumatic drugs (SAARDs) in rheumatoid arthritis. Ann Rheum Dis 1992; 51: 424-9.

21 van der Heijde D M, van Riel P L, Nuver-Zwart I $H$ Gribnau F W, van de Putte L B. Effects of hydroxychloroquine and sulphasalazine on progression of joint damage in rheumatoid arthritis. Lancet 1989; i:

22 Scott D L, Dawes P T, Fowler P D, Grindulis K A, Shadforth M, Bacon P A. Anti-rheumatic drugs and joint damage in rheumatoid arthritis. $Q \mathcal{F} \mathrm{Med} 1985$; 54: 49-59.

23 Pullar T, Hunter J A, Capell H A. Effect of sulphasalazine on the radiological progression of rheumatoid arthritis. Ann Rheum Dis 1987; 46: 398-402.

24 Capell H A, Murphy E A, Hunter J A. Rheumatoid arthritis: workload and outcome over 10 years. $Q \mathcal{F}$ Med 1991; 79: 461-76.

25 Paulus H E, Egger M J, Ward J R, Williams H J. Cooperative Systematic Studies of Rheumatic Diseases Group. Analysis of improvement in individual rheumatoid arthritis patients treated with disease-modifying antiarthritis patients treated with disease-modifying anti-
rheumatic drugs, based on the findings in patients treated with placebo. Arthritis Rheum 1990; 33: 477-84. 